
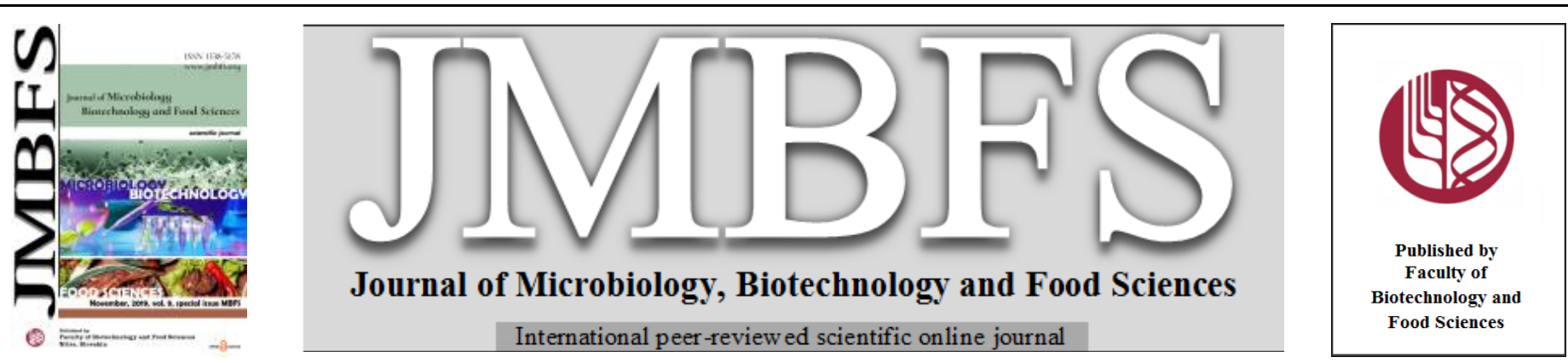

\title{
ISOLATION OF MONOCYTES FROM BOVINE BLOOD FOR PURPOSES OF CULTURE OF DENDRITIC CELLS
}

\author{
Lucie Kratochvilova ${ }^{1}$, Karmela Coufalova ${ }^{1}$, Monika Zouharova ${ }^{2}$, Maria Szczotka ${ }^{3}$, Petr Slama ${ }^{*, 1}$
}

Address(es): Ing. Petr Slama, Ph.D.

${ }^{1}$ Mendel University, Faculty of AgriSciences, Department of Animal Morphology, Physiology and Genetics, Zemedelska 1, 61300 Brno, Czech Republic, phone number: +420 545133146 .

${ }^{2}$ Veterinary Research Institute, Department of Immunology, Hudcova 296/70,621 00 Brno, Czech Republic.

${ }^{3}$ National Veterinary Research Institute, Department of Biochemistry, 57 Partyzantów Avenue, 24-100 Pulawy, Poland.

*Corresponding author: petr.slama@mendelu.cz

doi: 10.15414/jmbfs.2019.9.special.427-430

\section{ARTICLE INFO}

Received 18. 6. 2019

Revised 16. 9. 2019

Accepted 23. 9. 2019

Published 8. 11. 2019

Regular article

OPEN OACCESS

\begin{abstract}
Monocytes comprise a population of mononuclear leukocytes. In this article, we compare methods for isolating monocytes and also their cultivation into dendritic cells. Bovine blood collected from the vena jugularis externa was used for the experiment. This blood was used for isolating monocytes based on density gradient of OptiPrep or Histopaque solutions. The results indicated that the more efficient method is isolation based on density gradient of the Histopaque solution and subsequent magnetic separation of the cells. The monocyte population was further cultivated for $72 \mathrm{~h}$ with IL-4 and GM-CSF. The cells were evaluated under a light microscope, and it was apparent that CD14-positive cells transformed to dendritic cells. The second method using the Histopaque solution and magnetic separation was more efficient for the subsequent culture of dendritic cells.
\end{abstract}

Keywords: dendritic cell, monocyte, leukocyte, CD14, light microscopy

\section{INTRODUCTION}

Monocytes are cells originating from bone marrow hematopoietic stem cells through CFU-GEMM, CFU-GM, and CFU-M under the influence of cytokines IL-4, GM-CSF, and M-CSF. Monocytes comprise a population of mononuclear leukocytes developing in bone marrow from dividing monoblasts and are released into the bloodstream as non-dividing cells. They then permeate further into tissues. If monocytes do not initiate the journey into other tissues, they remain in the blood, where over time they mature or reduce the intensity at which their surface molecules are expressed and transform into so-called "resident" monocytes (Ginhoux et al., 2014; Toman, 2009). The size of a mature monocyte is $20-25 \mu \mathrm{m}$. These blood cells comprise several populations of cells differing in the intensity of their expression of several surface molecules (e.g., CD16, CD43, CD163, Ly6C, chemokine receptors). Monocytes are morphologically and phenotypically heterogeneous. This is why the term "monocyte" may be used to describe cells with similar appearance but different functions (Muller, 2001, Toman, 2009). Monocytes constitute a heterogeneous population of circulating phagocytes leading to the occurrence of a tissue population of macrophages and dendritic cells (DCs) under homeostatic and inflammatory conditions (Terry et al., 2014). These cells also circulate in the blood, bone marrow, and spleen, and they do not proliferate in a stable condition. They also can differentiate into inflammatory DCs or macrophages during inflammation (Geissmann et al., 2010). They can provide immunity oversight in certain tissues (Toman, 2009).

The DCs leukocyte population plays a significant role in connecting innate and acquired immunity. DCs are antigen-presenting cells with a unique method of initiating an immune response. DCs capture and transfer information from the surrounding environment into cells of the adaptive immune system. They may be important also for initiating immunological tolerance and regulating an immune response mediated by $\mathrm{T}$ cells (Banchereau et al., 2000). DCs are able to communicate with T cells, and they demonstrate a high level of MHC II and integrin CD11c. They originate from hematopoietic stem cells in bone marrow. DCs can be divided into two functionally distinct populations or lines. These are cells of myeloid and lymphoid origin (Toman, 2009). The myeloid line is represented by two subpopulations of CD11c+ cells: CD1c and CD141. Myeloid DCs are formed in bone marrow from a precursor common to macrophages. The lymphoid line issues plasmacytoid DCs, which altogether lack expression of $\mathrm{CD} 11 \mathrm{c}$ or produce it only in small amounts and are described by expression of antigens CD303, CD304, and CD123. Myeloid DCs capture antigens on the periphery and move them to areas of $\mathrm{T}$ cells initiating immunity, whereas lymphoid DCs are located in areas of the T cells and thymus and have regulatory and tolerogenic effects. Myeloid and lymphoid DCs may also differ in their precursors and cytokine activators (Steinman and Inaba, 1999). DCs have typical protrusions, so-called dendrites. This shape facilitates their movement, and they are able to migrate and to communicate with T lymphocytes (Ross et al., 2000).

The aim of this study was to compare methods for isolation of bovine blood monocytes and subsequent cultivation of isolated monocytes into DCs.

\section{MATERIAL AND METHODS}

Two methods that can be used for isolating monocytes from whole bovine blood were utilized. It is assumed that the monocytes acquired through these methods will be viable and further usable for in vitro cultivation. It is possible to acquire DCs by cultivating monocytes.

Isolation of monocytes on the basis of density gradient using OptiPrep solution

For this experiment, we used OptiPrep solution (Sigma-Aldrich, USA) while following the method published by Graham (2002). This publication described a method for isolating monocytes, albeit focused on human blood. Therefore, this methodology was adjusted to our purposes for isolating blood monocytes of cattle.

Blood was collected from six clinically healthy virgin heifers, age 18 months, cross-breeds of Holstein and Czech Fleckvieh. The animals were housed in the conditions of the experimental stable of the Veterinary Research Institute in Brno. Blood was collected from the vena jugularis externa in the amount of 10 $\mathrm{mL}$. EDTA (ethylenediaminetetraacetic acid) was used as anticoagulant. A $40 \%$ working solution was prepared by diluting the OptiPrep solution, using four parts OptiPrep to two parts of RPMI 1640 medium (Roswell Park Memorial Institute, Sigma-Aldrich, USA). This resulted in a solution with density of $1.217 \mathrm{~g} / \mathrm{mL}$. This solution was further diluted with the RPMI 1640 medium to density of 1.077 $\mathrm{g} / \mathrm{mL}$. Subsequently, $4.24 \mathrm{~mL}$ of the solution with density of $1.217 \mathrm{~g} / \mathrm{mL}$ was mixed with whole blood. This blood $(5 \mathrm{~mL})$ was carefully covered with a layer of the solution with density of $1.077 \mathrm{~g} / \mathrm{mL}$ using a Pasteur pipette and carefully poured over with $0.5 \mathrm{~mL}$ of the RPMI 1640 medium. This was followed by centrifugation $(700 \mathrm{~g})$ for 30 minutes. After the centrifugation, cells from the upper layer of the test tube column were collected. The viability of these cells 
was assessed by trypan blue exclusion. The method utilizes the various densities of the individual types of white blood cells. The acquired cells were stained using the Pappenheim staining method (Doubek, 2003). A microscope slide was smeared with a suspension of the cells that had been stained using MayGrünwald solution for 3 minutes. Distilled water was then added ( 25 drops over 1-2 minutes). The solution was then poured off from the slide, GiemsaRomanovski stain (diluted $10 \times$ ) was used for 15 to 20 minutes. The solution was then again poured off from the slide, washed with distilled water, and dried. The cells were then observed under an Olympus BX51 microscope with PROMICAM 3-5CP digital camera (5Mpx SONY PREGIUS CMOUS USB 3.0) and using the software QuickPHOTO MICRO 3.2 (PROMICRA).

Isolation of monocytes on the basis of density gradient using Histopaque solution and magnetic separation of cells

Histopaque solution (Sigma-Aldrich, USA) was used in this experiment along with the technique of separating cells using magnetic microbeads (MicroBeads, Miltenyi Biotec, Germany), as described by Szczotka et al. (2009). Blood was taken from six clinically healthy heifers 18 months of age. The blood was taken from the vena jugularis externa in an amount of $100 \mathrm{~mL}$. EDTA was again used as anticoagulant. The blood was centrifuged (2100 rpm), and then the buffy coat (i.e., leukocytes layer) was collected together with some of the surrounding erythrocytes and blood plasma. Subsequently, the Histopaque solution was used (density 1.077). Histopaque was placed into a test tube and softly layered over with blood, specifically the buffy coat + part of erythrocytes + part of blood plasma mixture. This test tube, with the contents as described, was centrifuged for $1 \mathrm{~h}(2100 \mathrm{rpm})$. The layer of mononuclear cells (monocytes and lymphocytes) was then acquired. This suspension of cells was further marked with microbeads (CD14 MicroBeads, human, Miltenyi Biotec, Germany) In this manner, antibodies with microbeads were attached to CD14-positive cells Subsequently, the CD14-positive cells (i.e., monocytes) were acquired using a magnetic separator. The viability of cells was evaluated using trypan blue exclusion. The purity of monocytes was tested by marking the cells with the CD11c surface molecule, followed by analysis in a BriCyte E6 flow cytometer (Mindray, China). The acquired cells were stained using the Pappenheim method (Doubek, 2003), as in the previous experiment. The cells were also observed under a light microscope, as in the previous experiment.

\section{Cultivation of CD14-positive cells}

Cells acquired by magnetic separation (CD14+, monocytes) were used for cultivation into DCs. Cultivation was performed in cell culture flasks (NuncTM Eas YFlaskTM Cell Culture Flasks, Thermo Fisher Scientific) within an incubator at temperature $37{ }^{\circ} \mathrm{C}$ in an atmosphere of $5 \% \mathrm{CO}_{2}$. The cells were cultivated for $72 \mathrm{~h}$. Cytokines IL-4 and GM-CSF (bovine dendritic cell growth kit, Bio-Rad) were used as growth factors and were part of the RPMI 1640 medium, into which antibiotics were added - 10,000 units penicillin, $10 \mathrm{mg}$ streptomycin, and $25 \mu \mathrm{g}$ amphotericin B per ml (Antibiotic Antimycotic Solution, Sigma-Aldrich, USA) After cultivation, the cells were again observed by light microscopy, using the same microscope as in the previous sub-experiments.

\section{RESULTS AND DISCUSSION}

Isolation of monocytes on the basis of density gradient using OptiPrep solution

The first experiment was focused on isolating monocytes from cattle blood using the methodology from Graham (2002). This method had appeared very suitable considering the speed of isolation. Unfortunately, the methodology does not ensure acquiring a pure population of monocytes, as stated by Graham (2002) This method succeeded only in acquiring a population of mononuclear cells (i.e., a mixture of monocytes and lymphocytes) along with a small number of erythrocytes and granulocytes (in all measurements $<5 \%$ ). The viability of cells assessed by trypan blue exclusion was $>98 \%$ in all samples. The population of the acquired cells can be seen in Figure 1.

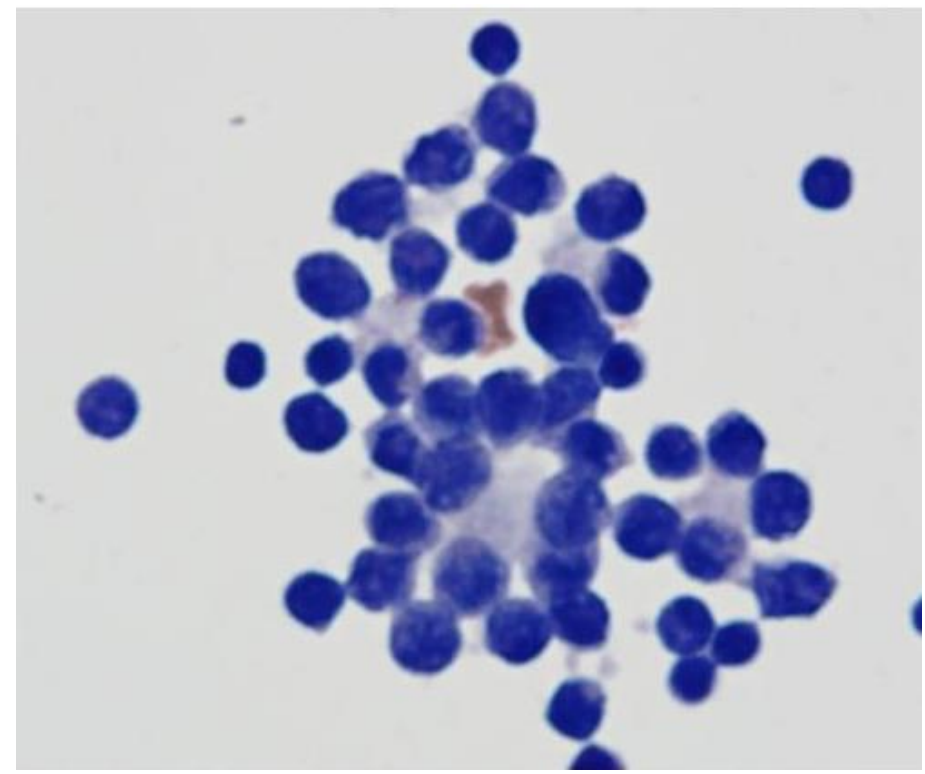

Figure 1 Population of the acquired cells (1000× magnification)

Isolation of monocytes on the basis of density gradient using Histopaque solution and magnetic separation of cells

The second experiment utilized a Histopaque solution and the technique of separating monocytes using magnetic microbeads marked for CD14, in accordance with Szczotka et al. (2009). After isolation with the Histopaque solution, a mononuclear cell population with $>99 \%$ purity was acquired. Using magnetic separation, a cell population with $>90 \%$ monocytes was acquired Monocytes are shown in Figure 2. The purity of the monocyte population was verified using flow cytometry by marking cells on CD11c. The viability of cells evaluated by trypan blue exclusion was $>99 \%$ for all samples.

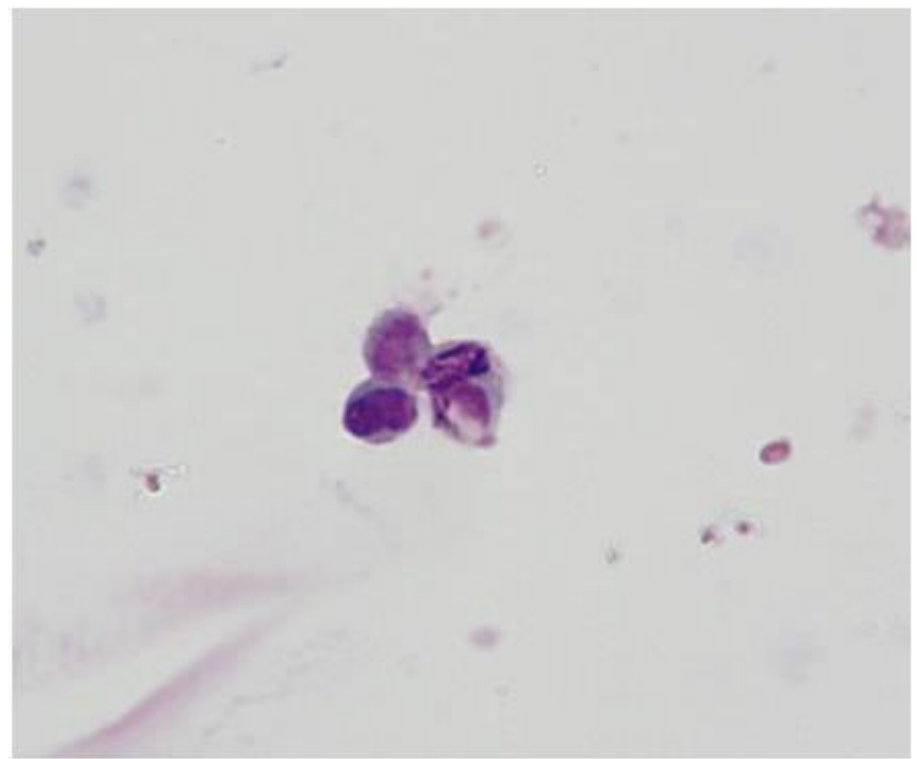

Figure 2 Monocytes $(1000 \times$ magnification)

\section{Cultivation of CD14-positive cells}

Cells acquired by magnetic separation in the previous experiment were used for cultivation into DCs. It was analyzed whether these cells were viable and suitable for cultivation into DCs. Short-term cultivation $(72 \mathrm{~h})$ was used. After this cultivation, the cells were analyzed by microscope and then photographed. As shown in the following figures, after 3 days of incubation, the CD14-positive cells were transforming into DCs. The following figures show the CD14-positive cells in various stages of maturing into DCs (Figures 3, 4, and 5). 


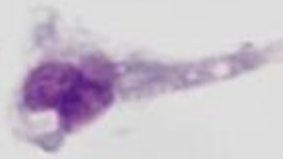

Figure 3 Monocyte transforming into DC (1000× magnification)
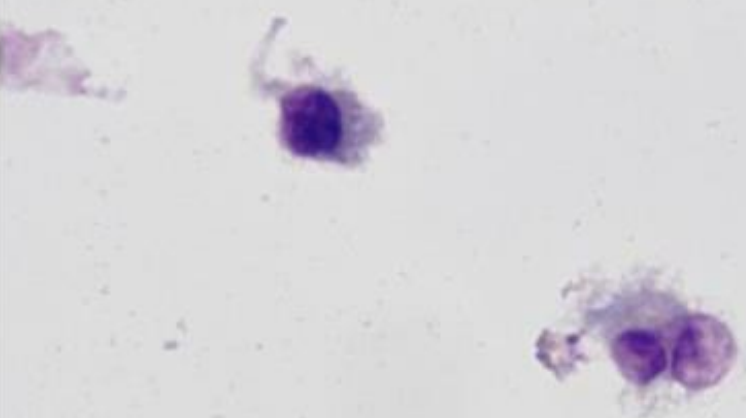

Figure 4 Monocytes in various stages of maturing into DCs (1000× magnification)

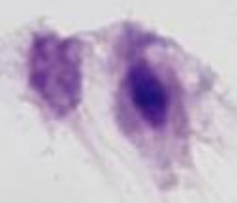

Figure 5 Cells with marked protrusions typical of DCs (1000× magnification)
The main objective of these experiments was to determine which of the two selected methods would be more efficient in isolating a pure population of monocytes that would then be suitable for cultivation into DCs. As shown in our results above, the more efficient method appears to be that of Szczotka et al (2009). Bovine blood was used for this experiment. The number of monocytes in normal bovine blood was low due to a low representation of these cells in the blood. Their percentage representation in differential count in cattle is $3-5 \%$ (Doubek, 2003). After magnetic separation of cells, enriched fractions of marked cells were acquired. CD14-positive cells had the large nucleus and lower representation of cytoplasm typical for the morphology of a monocyte. After $72 \mathrm{~h}$ of cultivation, the cells had created dendrites. Morphological characteristics were evaluated using light microscopy. The development of these cells corresponds to their early stage of maturing. It is nevertheless apparent that each cell develops individually, as the cells in the samples were in different stages of development, ranging from small signs of protrusions to typical elongated protrusions. Based on the information in his publication, the method according to Graham (2002) was supposed to be very efficient in acquiring a pure population of monocytes. We cannot, however, fully agree with this, because even with the most careful procedure and while precisely following the methodical instructions, this method cannot lead to acquiring a completely pure population of monocytes but only a population of mononuclear cells (i.e., a mixture of monocytes and lymphocytes) We therefore consider the conclusions of said study to be quite misleading. The development of DCs over time, after isolation from monocytes and subsequent cultivation, can be as follows: After $24 \mathrm{~h}$ of cultivation, monocytes start to transform into DCs. After $72 \mathrm{~h}$ of cultivation, dendrites typical of DCs are forming (Szczotka et al., 2009). The following methods are used for isolating leukocytes: hypotonic lysis of erythrocytes, lysis of erythrocytes using FACS lysing solution, lysis of erythrocytes using $\mathrm{NH}_{4} \mathrm{Cl}$ and density gradient (Slama et al., 2006). We have excluded some of these methods from our narrow selection. For this study, we selected the methods of isolation using density gradient. In our opinion, the method used by Szczotka et al. (2009) is a promising one and could be used also for subsequent long-term cultivation into DCs. Studies are being conducted in human medicine for use of these cells to induce anti-tumor immunity. In such studies, isolated monocytes are prepared into DCs with a specific tumor antigen added, and after processing the cells are returned to the patient's body. Such cells can be then used for various other immunotherapies and in transplants. Use of these cells in treating HIV also is being considered Another publication describes the use of DCs for tumor immunotherapy (Bol et al., 2019). Isolation of monocytes remain a topic of current interest, as evidenced for example, by a study on possibilities of separating monocytes and their subsequent use (Kim et al., 2019). Monocytes in resting stage complement tissue-resident macrophages and DCs (Chow et al., 2011). In case of proinflammatory, metabolic, and immunity stimuli, their access and differentiation into macrophages and DCs are rapidly increasing. Through differentiation, they contribute to defense capability, tissue remodeling, and healing (Zawada et al. 2012). Monocytes are capable of producing inflammatory cytokines (Abbas at al., 2014). By means of receptors that detect pathogens, they can remove various biological substances and toxic molecules (Gordon and Taylor, 2005).

\section{CONCLUSION}

In this article, we describe populations of DCs and monocytes and leukocyte isolation techniques. The objective of the experiment was to select a suitable method for isolating monocytes for subsequent cultivation into DCs. Two methods were selected, the first one had been developed by Graham (2002) using the OptiPrep solution. This method proved to be unsuitable for isolation of monocytes from cattle blood. The second method, developed by Szczotka et al (2009) using the Histopaque solution and magnetic separation, was more efficient for isolation of monocytes from cattle blood. It was determined that cells acquired by magnetic separation were suitable for cultivation into DCs. These cells have a strong potential for treatment of various diseases, including mastitis in cattle. We plan to investigate the possibility of DCs to recognize Streptococcus uberis adhesion molecule (SUAM) and present this information to lymphocytes during mammary gland inflammation caused by Streptococcus uberis.

Acknowledgments: The authors wish to express their thanks for financial support to the projects of IGA AF MENDELU No. AF-IGA-IP-2018/032 and AF-IGA-2018-tym002 and to the project of the Ministry of Agriculture of the Czech Republic No. QK1910212.

\section{REFERENCES}

Abbas, K., Lichman, A., \& Pillai, S. (2014). Cellular and Molecular Immunology, 7th Edition. Philadelphia: Saunders/Elsevier.

Banchereau, J., Briere, F., Caux, C., Davoust, J., Lebecque, S., Liu, Y.-J.,

Palucka, K. (2000). Immunobiology of Dendritic Cells. Annual Review of Immunology, $18(1)$,

$767-811$ 
Bol, K. F., Schreibelt, G., Rabold, K., Wculek, S. K., Schwarze, J. K., Dzionek, A., ... de Vries, I. J. M. (2019). The clinical application of cancer immunotherapy based on naturally circulating dendritic cells. Journal for ImmunoTherapy of Cancer, 7(1). http://dx.doi.org/10.1186/s40425-019-0580-6

Ginhoux, F., \& Jung, S. (2014). Monocytes and macrophages: developmental pathways and tissue homeostasis. Nature Reviews Immunology, 14(6), 392-404. http://dx.doi.org/10.1038/nri3671

Gordon, S., \& Taylor, P. R. (2005). Monocyte and macrophage heterogeneity. Nature Reviews Immunology, 5(12), 953-964. http://dx.doi.org/10.1038/nri1733 Graham, J. (2002). Separation of Monocytes from Whole Human Blood. The $\begin{array}{llll}\text { Scientific World } & \text { JOURNAL, } & 1540-1543 .\end{array}$ http://dx.doi.org/10.1100/tsw.2002.842

Geissmann, F., Manz, M. G., Jung, S., Sieweke, M. H., Merad, M., \& Ley, K. (2010). Development of Monocytes, Macrophages, and Dendritic Cells. Science, 327(5966), 656-661. http://dx.doi.org/10.1126/science.1178331

Chow, A., Brown, B. D., \& Merad, M. (2011). Studying the mononuclear phagocyte system in the molecular age. Nature Reviews Immunology, 11(11), 788-798. http://dx.doi.org/10.1038/nri3087

Doubek, J. (2003). Veterinární hematologie. Brno: Noviko,

Kim, J., Gómez-Pastora, J., Weigand, M., Potgieter, M., A. Walters, N., Reátegui, E., ... Chalmers, J. J. (2019). A Subpopulation of Monocytes in Normal Human Blood Has Significant Magnetic Susceptibility: Quantification and Potential Implications. Cytometry Part A, 95(5), 478-487. http://dx.doi.org/10.1002/cyto.a.23755

Muller, W. A. (2001). New mechanisms and pathways for monocyte recruitment. $J$ Exp Med, 194, 47-51

Ross, R., Jonuleit, H., Bros, M., Ross, X.-L., Enk, A. H., Knop, J., ..

Matsumura, F. (2000). Expression of the Actin-Bundling Protein Fascin in Cultured Human Dendritic Cells Correlates with Dendritic Morphology and Cell Differentiation. Journal of Investigative Dermatology, 115(4), 658-663. http://dx.doi.org/10.1046/j.1523-1747.2000.00112.x

Sláma, P., Sládek, Z., \& Ryšánek, D. (2006). Effect of Isolation Techniques on Viability of Bovine Blood Neutrophils. Acta Veterinaria Brno, 75(3), 343-353. http://dx.doi.org/10.2754/avb200675030343

Steinman, R. M., \& Inaba, K. (1999). Myeloid dendritic cells. Journal of Leukocyte Biology, 66(2), 205-208. http://dx.doi.org/10.1002/jlb.66.2.205

Szczotka, M., Kuzmak, J., \& Kubis, P. (2009). Bovine blood dendritic cells: isolation and morphology. Bull Vet Inst Pulawy, 53, 687-691.

Toman, M. (2009). Veterinární imunologie. 2nd Edition, Prague: Grada.

Terry, R. L., \& Miller, S. D. (2014). Molecular control of monocyte development. Cellular Immunology, 291(1-2), 16-21. http://dx.doi.org/10.1016/j.cellimm.2014.02.008

Zawada, A. M., Rogacev, K. S., Schirmer, S. H., Sester, M., Böhm, M., Fliser, D., \& Heine, G. H. (2012). Monocyte heterogeneity in human cardiovascular disease. Immunobiology, 217(12) $1273-1284$ http://dx.doi.org/10.1016/j.imbio.2012.07.001 